\title{
EXTRAÇÃO DE ÓLEOS ESSENCIAIS DE MALVAVISCUS ARBOREUS: UMA NOVA PERSPECTIVA NO ENFRENTAMENTO DO AEDES AEGYPTI
}

\author{
E. S. SANTANA ${ }^{1}$; L. L. SANTOS ${ }^{1}$; D. B. S. SILVA ${ }^{1}$; L. S. OLIVEIRA ${ }^{1}$; T. R. S. NUNES ${ }^{2}$; \\ D. C. F. VIANA ${ }^{2}$; B. C. ARAÚJO' ${ }^{2}$ M. G. R. PITTA ${ }^{2}$; C. A. S. ANDRADE ${ }^{1,2}$; M. D. L. \\ OLIVEIRA $^{1,2}$
}

\footnotetext{
${ }^{1}$ Laboratório de Biodispositivos Nanoestruturados - Departamento de Bioquímica UFPE

${ }^{2}$ Programa de Pós-graduação em Inovação Terapêutica- UFPE
}

$$
\text { E-mail para contato: eduardabio14@gmail.com }
$$

\begin{abstract}
RESUMO - As arboviroses têm se tornado uma grande ameaça para saúde da sociedade nos tempos atuais. Atualmente, o mosquito Aedes aegypti vem ganhando destaque devido a possibilidade de transmissão de arboviroses a humanos, dentre elas a Dengue, zika e chikungunya. Sendo o Zika vírus relacionado ao aumento de casos de microcefalia e de manifestações neurológicas associadas à ocorrência da doença. Com isso, diversas campanhas foram realizas para divulgar estratégias no combate ao vetor, entre elas a extração de óleos essências de plantas medicinais para o desenvolvimento de repelentes. Desta forma, o estudo em questão teve por objetivo, a extração de óleos essenciais, que possuem componentes químicos presentes nos metabólicos secundários das plantas como terpenóides e fenilpropanóides, que possuem um grande potencial de ação no controle de fitopatógenos. A planta escolhida para o desenvolvimento do estudo foi Malvaviscus arboreus - conhecida popularmente como malva-decolibri, sendo reconhecida por seus propósitos medicinais dentro de uma série de culturas indígenas. A coleta da planta foi realizada na cidade de Carpina no mês de julho de 2017, que por meio do processo de hidrodestilação foi feita a extração do óleo essencial. As folhas da planta foram trituradas e colocadas junto a água deionizada em temperatura máxima de $100{ }^{\circ} \mathrm{C}$ no aparelho graduado Clevenger, sendo assim extraído o óleo essencial, com um rendimento de 0,556g do mesmo para $300 \mathrm{~g}$ de folhas, com perspectivas futuras do desenvolvimento de um repelente natural para o combate ao mosquito Aedes aegypti e o enfrentamento do vírus Zika.
\end{abstract}

Palavras chaves: Arboviroses; fitopatógenos; repelente.

ABSTRACT - Arboviruses have become a major threat to society's health. in the present times. Currently, the Aedes aegypti mosquito gaining featured due to the possibility of transmission of arboviruses to humans, among them Dengue, zika 
and chikungunya. Being the Zika virus related to the increase of cases of microcephaly and neurological manifestations associated with the occurrence of disease. With this, several campaigns were carried out to disseminate strategies in the combating the vector, among them the extraction of essential oils from medicinal plants for development of repellents. In this way, the objective of the study was to extraction of essential oils, which have chemical components present in secondary metabolites of plants such as terpenoids and phenylpropanoids, which have a great potential of action in the control of phytopathogens. The plant chosen for the study development was Malvaviscus arboreus - popularly known as malvade-colibri, being recognized for its medicinal purposes within a series of indigenous cultures. The plant was collected in the city of Carpina in the month of July 2017, that through the hydrodistillation process the oil was extracted essential. The leaves of the plant were crushed and placed next to deionized water at a maximum temperature of $100{ }^{\circ} \mathrm{C}$ on the Clevenger graduated unit, whereby the essential oil was extracted in a yield of $0.556 \mathrm{~g}$ of the same to $300 \mathrm{~g}$ of leaves with future prospects for the development of a natural repellent for the control of the Aedes aegypti mosquito against the Zika virus.

Keywords: Arboviroses; phytopathogens; insect repellents.

\section{INTRODUÇÃO}

As arboviroses têm se tornado importantes e constantes ameaças em regiões tropicais devido às rápidas mudanças climáticas, desmatamentos, migração populacional, ocupação desordenada de áreas urbanas, precariedade das condições sanitárias que favorecem a amplificação e transmissão viral(RUST, 2012). Ao longo dos anos o mosquito Aedes aegypti vem ganhando destaque devido a possibilidade de transmissão de arboviroses a humanos, dentre essas a Dengue é a mais conhecida (LOPES, 2017). No ano de 2014 houve a catalogação da zika ou chikungunya como arboviroses transmitidas pelo Aedes aegypti. Recentemente, o Zika vírus ganhou destaque devido a ocorrência de óbitos pelo agravo, aumento dos casos de microcefalia e de manifestações neurológicas associadas à ocorrência da doença (WORLD, 2016).

A utilização de plantas medicinais para fins profiláticos e curativos é uma prática tradicional, amplamente difundida na medicina popular. Assim podem ser destacados os óleos essências no desenvolvimento de repelentes, que são constituídos por substâncias aplicadas sobre a pele, roupas e superfícies que desencorajam a aproximação dos mosquitos. Seu uso reduz o risco de transmissão de inúmeras doenças infecciosas e reações imunoalérgicas resultantes da picada desses artrópodes.

O uso de plantas para extração de óleos essências com os componentes químicos monoterpenoides, sesquiterpenoides e fenilpropanóides, possuem um grande potencial de ação no controle de fitopatógenos, podendo ser observado também através de testes biológicos e farmacológicos uma fonte valiosa de mosquitocidas, antifúngicas, agentes antitumorais e hemostáticos (BRU et al., 2016) nesses fitoterápicos. Estudos vistos na literatura mostraram o potencial da planta Malvaviscus arboreus como analgésicos, hemostáticos e para curar as picadas de insetos, contendo uma mistura variável de terpenóides, fenilalcanóides, amidas e flavonóides (BRU et al., 2016). Com isso o presente trabalho tem como objetivo a extração de óleos essenciais, pelo processo de hidrodestilação da planta medicinal Malvaviscus arboreus - conhecida popularmente como malva-de-colibri para o futuro desenvolvimento de um repelente natural para o combate ao $A$. aegypti e o enfrentamento do vírus Zika. 


\section{MATERIAIS E MÉTODOS}

A coleta das folhas da planta Malvaviscus arboreus (Figura 1) conhecida popularmente como malva-de-colibri foi feita na cidade Carpina, no mês de julho de 2017, onde foi realizada a separação da folha do caule, além da eliminação das folhas que apresentaram contaminação por fungos. Em seguida as folhas foram lavadas para uma melhor higienização, trituradas e armazenadas na câmera fria do Departamento de Bioquímica da Universidade Federal de Pernambuco(UFPE) até o início do processo de hidrodestilação.

Figura 1- Folha da planta Malvaviscus arboreus

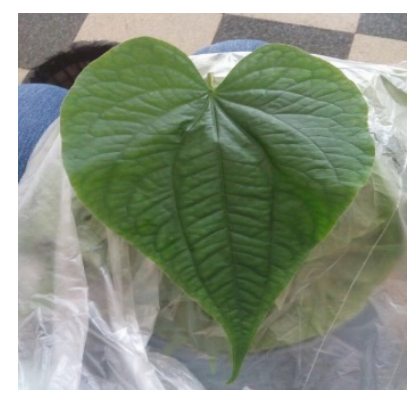

Fonte: O autor, 2017.

Os óleos essenciais foram obtidos através da hidrodestilação em aparelho graduado Clevenger, usando-se $300 \mathrm{~g}$ das folhas trituradas, para cada grama de folha foi utilizada $1 \mathrm{~L}$ de água deionizada, em temperatura máxima de $100{ }^{\circ} \mathrm{C}$ até atingir a fervura, reduzindo-se posteriormente para $75^{\circ} \mathrm{C}$, por um período de aproximadamente $2 \mathrm{~h}$. Ao final, o óleo essencial foi coletado com uma pipeta e armazenado em eppendorf protegido da luz com papel alumínio. Para a determinação do rendimento do óleo essencial extraído por hidrodestilação de cada $300 \mathrm{~g}$ das espécies vegetais foi pesado o eppendorf vazio em balança analítica e posteriormente o eppendorf com o óleo essencial extraído da planta.

\section{RESULTADOS E DISCUSSÃO}

O rendimento do óleo essencial a partir de $300 \mathrm{~g}$ de folhas picadas, sendo para cada grama de folhas $1 \mathrm{~L}$ de água deionizada, totalizou-se em $0,556 \mathrm{~g}$. Os níveis de rendimento dos óleos essenciais podem ser influenciados por uma série de fatores, dentre eles o tempo de hidrodestilação utilizado para a extração do óleo essencial, que pode gerar significativas alterações na obtenção dos óleos essenciais. Segundo Charles e Simon (1990), o método de extração utilizado para a obtenção do óleo essencial influencia no seu conteúdo. Técnicas comumente empregadas para extração de óleos essenciais incluem a destilação a vapor, hidrodestilação, extração por solventes entre outras (GUENTHER, 1972). Evidências atuais corroboram a ampla utilização de espécies herbáceas nos sistemas de prevenção a doenças, pois as plantas tendem a investir em compostos secundários de alta atividade biológica, como alcaloides, glicosídeos e terpenóides (STEPP E MOERMAN 2001), o que possibilita a aderência a esse tipo de pesquisa em prol da para obtenção de produtos com melhores resultados em virtude da diminuição de doenças preocupantes causadas por arboviroses em determinadas comunidades. 


\section{CONCLUSÃO}

INOVAÇÃO TERAPEUUTICA

A pesquisa permitiu a inovação através da extração do óleo essencial da planta do gênero Malvaíscus arboreus em virtude da sua ação contra arboviroses responsáveis por veicular doenças alarmantes na sociedade, uma vez que esse fitoterápico possui atividade de repelência contra os agentes citados é considerável validar esse víeis no âmbito científico com o aprofundamento de estudos relacionados à outras plantas para obtenção de informações, em conseqüência dessa análise, o aprofundamento em conhecimentos característicos do alto índice exploratório de recursos naturais voltados ao seu exercício associando-o às perspectivas científicas.

\section{REFERÊNCIAS}

CHARLES, D.J.; SIMON, J.E. Comparison of extraction methods for the rapid determination of essential oil content and composition of basil (Ocimum spp.). Journal of the American Society for Horticultural Science, v.115, n.3, p.458-62, 1990

GIRALDI, M. \& HANAZAKI, N. 2010. Uso e conhecimento tradicional de plantas medicinais no Sertão do Ribeirão. Acta Botanica Brasilica,24(2.): 395-406.

GUENTHER, E The Production of Essential Oils. In. The essential oils. New York: d.Van Nostrand Co. v.1, p.87- 226, 1972.

BRU, J.; JUAN D. GUZMAN. Folk medicine, phytochemistry and pharmacological application of Piper marginatum. Revista Brasileira de Farmacognosia 26 (2016) 767-779.

RUST RS. Human arboviral encephalitis. Semin Pediatr Neurol. 2012 Sep;19(3):130-51. LOPES, N.; NOZAWA, C.; LINHARES, R. E. C. Características gerais e epidemiologia dos arbovírus emergentes no Brasil. Rev Pan-Amaz Saude, Ananindeua, v. 5, n. 3, p. 55-64, set. 2014.

STEPP, J.R.; MOERMAN, D.E. 2001. The importance of weeds in ethnopharmacology. Journal of Ethnopharmacology, 75: 19-23.

WORLD HEALTH ORGANIZATION. Zika: Public Health Emergency of International Concern (2016). Disponivel em: <www.who.int/emergencies/zika-virus/en/> Acesso em: 02 nov 2017.

\section{AGRADECIMENTOS}

Os autores agradecem à Universidade Federal de Pernambuco (UFPE), à Incubadora de Tecnologias Sociais da Universidade Federal de Pernambuco, ao apoio de bolsas em iniciação à extensão da PROExC-UFPE, às mulheres da comunidade da Muribeca e à Escola de Referência em Ensino Médio Edson Moury Fernandes (EREMEMF). 